\title{
Body mass index centile charts to assess fatness of British children
}

\author{
E M White, A C Wilson, S A Greene, C McCowan, G E Thomas, A Y Cairns, \\ I W Ricketts
}

\author{
Centre for Research \\ into Human \\ Development, \\ Department of Child \\ Health, Ninewells \\ Hospital and \\ Medical School, \\ Dundee DD1 9SY \\ E M White \\ A C Wilson \\ S A Greene \\ C McCowan \\ Department of \\ Mathematics and \\ Computer Science, \\ University of Dundee \\ G E Thomas \\ A Y Cairns \\ I W Ricketts \\ Correspondence to: \\ E $M$ White. \\ Accepted 5 October 1994
}

\begin{abstract}
Body mass index (BMI) relates weight to height and reflects the shape of a child, but because of age dependency it has not been used conventionally for the estimation of fatness in children. From measurements of Tayside children $(n=34$ 533) centile charts were constructed for BMI (wt/ht ${ }^{2}$ ) from the raw data of height and weight, using Cole's LMS method for normalised growth standards. These data were compared with the only available European BMI charts published from data of French children obtained over a period of 24 years from 1956-79. British children appear to be 'fatter'. Within a subgroup $(n=445)$ the $B M I$ values were correlated with estimations of body fat, for boys and girls, from skinfold thickness $(r=0.8$ and 0.81$)$ and bioelectrical impedance $(r=0.65$ and 0.7$)$. The limits of acceptable BMI have yet to be defined. (Arch Dis Child 1995; 72: 38-41)
\end{abstract}

Keywords: childhood obesity, body mass index centile charts, body fat estimation.

The adult physician's view is that obesity should be considered a chronic disease, is a definite hazard to health, and is one of the most important medical and public health problems of our time. ${ }^{1}$ In the past, paediatricians have shown little interest in childhood obesity because it was thought to be a temporary phase and bore no relation to adult obesity with its associated mortality and morbidity. ${ }^{2}$ Childhood obesity was considered difficult to assess and intervention programmes were of limited effect. ${ }^{3}$ However, a detailed study of a French cohort of children demonstrated that an index reflecting the fatness of children was valid and found $41 \%$ of obese adults had been obese children. Longitudinal monitoring has also identified children who are at risk of becoming obese adults. ${ }^{4}$ Cernerud, in a study of Swedish children, showed an increase in the body mass index (BMI; Quetelet index, wt/ht ${ }^{2}$ ) of boys and girls in the period $1970-90^{5}$ with a subsequent suggestion that decreased physical activity might be responsible for increased adiposity during these two decades. A detailed review of 17 published reports from 15 study populations found that across all ages, the risk of adult obesity was at least twice as high for obese children as it was for non-obese children. ${ }^{6}$
In theory, the]refore, the identification of children who will become obese adults may facilitate early intervention and avoidance of the morbidity and mortality associated with adult obesity. Assessment of body fat can be calculated from a variety of methods. Traditionally skinfold measurements and more recently estimations of total body water by bioelectrical impedance have been used in children, but these are inappropriate for screening large numbers of children in the community setting. BMI relates weight to height and is a better indicator of shape than weight alone. Although this measure is routinely and confidently used in assessment of adult adiposity, ${ }^{7}$ it is not conventionally used for the estimation of obesity in childhood, despite the ease of calculation.

We measured the distribution of body fat throughout childhood and for ease of calculation the Quetelet index, as recommended in the French study ${ }^{8}$ and by Cole, ${ }^{9}$ was chosen as the quantity to determine BMI standards. BMI centile charts were constructed and individual BMI values compared with those of estimates of body fat calculated from skinfold measurement and bioelectrical impedance in a subset of the study population. A comparison was also made with the only published standards for European children, calculated from measurements obtained in France between 1956-79. ${ }^{10}$

Smoothed $L, M$, and $S$ values for BMI at six monthly intervals

\begin{tabular}{|c|c|c|c|c|c|c|}
\hline \multirow{2}{*}{$\begin{array}{l}\text { Age } \\
\text { (years) }\end{array}$} & \multicolumn{2}{|l|}{$L$} & \multicolumn{2}{|l|}{$M$} & \multicolumn{2}{|l|}{$S$} \\
\hline & Boys & Girls & Boys & Girls & Boys & Girls \\
\hline $3 \cdot 0$ & -0.78 & $-0 \cdot 14$ & $16 \cdot 50$ & $16 \cdot 22$ & 0.082 & 0.08 \\
\hline 3.5 & -0.90 & 0.36 & 24 & 15.99 & 085 & 0.09 \\
\hline $4 \cdot 0$ & -1.04 & -0.58 & 16.01 & & .087 & 0.094 \\
\hline 4.5 & $-1 \cdot 15$ & -0.80 & 15.83 & $15 \cdot 66$ & 0.088 & 0.094 \\
\hline $5 \cdot 0$ & $-1 \cdot 27$ & -1.04 & 15.69 & $15 \cdot 57$ & 0.087 & 0.094 \\
\hline 5.5 & -1.38 & -1.27 & $15 \cdot 62$ & 15.55 & 0.087 & 0.095 \\
\hline 6.0 & -1.49 & $-1 \cdot 43$ & 15.63 & $15 \cdot 61$ & 0.087 & 0.097 \\
\hline 6.5 & -1.60 & -1.51 & $15 \cdot 71$ & & 0.089 & $0 \cdot 100$ \\
\hline $7 \cdot 0$ & -1.68 & -1.52 & $15 \cdot 83$ & $15 \cdot 89$ & 0.093 & $0 \cdot 104$ \\
\hline $7 \cdot 5$ & -1.72 & -1.47 & 15.96 & 16.06 & 0.097 & 0.109 \\
\hline $8 \cdot 0$ & $-1 \cdot 70$ & -1.39 & $16 \cdot 11$ & 16 & $0 \cdot 103$ & 0.115 \\
\hline $8 \cdot 5$ & -1.63 & $-1 \cdot 3$ & 16.27 & 16.42 & 0.108 & 0.121 \\
\hline $9 \cdot 0$ & -1.59 & $-1 \cdot 33$ & 16.46 & 16.66 & 0.113 & $0 \cdot 126$ \\
\hline $9 \cdot 5$ & $-1 \cdot 68$ & -1 . & 16.66 & 16 & $\cdot 116$ & 0.131 \\
\hline 10.0 & $-1 \cdot 80$ & $-1 \cdot 35$ & 16.86 & $17 \cdot 21$ & 0.118 & 0.135 \\
\hline 10.5 & -1.88 & $-1 \cdot 2$ & $17 \cdot 0$ & 17. & 20 & $0 \cdot 140$ \\
\hline $11 \cdot 0$ & -1.91 & $-1 \cdot 19$ & $17 \cdot 27$ & $17 \cdot 81$ & $0 \cdot 122$ & $0 \cdot 144$ \\
\hline 11.5 & & -1 . & $17 \cdot 50$ & & $0 \cdot 1$ & 0.147 \\
\hline 12.0 & -1.83 & -0.97 & $17 \cdot 76$ & 18.51 & 0.125 & 0.149 \\
\hline 12.5 & -1.75 & -0.87 & 18.04 & 18. & 0.1 & 0.149 \\
\hline 13.0 & -1.69 & -0.84 & $18 \cdot 34$ & $19 \cdot 3$ & $0 \cdot 127$ & 0.149 \\
\hline 13.5 & $-1 \cdot 66$ & -0.92 & 18.67 & $19{ }^{\circ}$ & 0.127 & 0.148 \\
\hline 14.0 & -1.68 & -1.09 & 19.02 & $20 \cdot 12$ & 0.127 & 0.146 \\
\hline 14.5 & -1.71 & $-1 \cdot 30$ & $19 \cdot 40$ & 20 & 0.127 & 0.144 \\
\hline 15.0 & -1.71 & $-1 \cdot 48$ & $19 \cdot 77$ & 20 . & $0 \cdot 127$ & $0 \cdot 144$ \\
\hline 15.5 & & -1.6 & $20 \cdot 12$ & 21 . & $0 \cdot 128$ & 0.143 \\
\hline 16. & -1.61 & -1.81 & $20 \cdot 47$ & $21 \cdot 62$ & $0 \cdot 130$ & $0 \cdot 143$ \\
\hline
\end{tabular}


Subjects and methods

Data was obtained from the Tayside Growth Study. This is an ongoing longitudinal growth study, started in 1989, with the initial remit of identifying the incidence and prevalence of short stature in a defined health area of Scotland. Heights and weights, of children aged $3,5,7,9,11$, and 14 years, obtained by primary health care staff (health visitors, general practitioners, clinical medical officers, school nurses) as part of the routine health surveillance programme are transferred to a central computer data base with an anthropometric analysis program. Approximately 17000 children every year have had height and weight measurements recorded. The data used for development of the BMI standards were collected in the period 1989-91: $n=34533$.

Parents and guardians of the children were sent a letter explaining the aims of the study and requesting permission to store and analyse by computer the growth data received from primary health care staff. All data were subject to the Data Protection Act. Height was measured using portable measuring devices such as the Minimetre (Raven Equipment Ltd; available from the Child Growth Foundation, 2 Mayfield Ave, London W4 1PW) or Microtoise (out of production) and weight by beam balance or portable scale. The measurements were performed by school nurses, health visitors, clinical medical officers, and general practitioners. Height measurement was validated by comparison of primary care staff measurements with those of a research nurse (EMW). The differences between the two sets of the measurements were analysed $(S D=0.5 \mathrm{~cm})$. This value compares favourably with the error of measurement noted in other community studies. ${ }^{11}$

A subset of 7 and 8 year old children of the study population was involved in a separate study (A Wilson. Tayside infant feeding

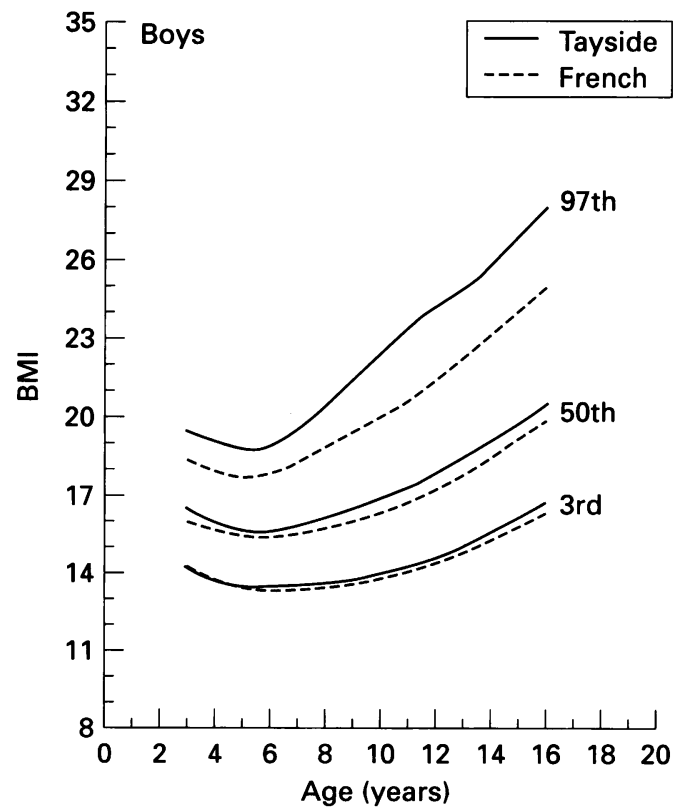

study; directed by Dr J S Forsyth: personal communication) and body fat was assessed in 445 subjects by skinfold (four sites; triceps, biceps, suprailiac, and scaphoid: analysis by the method according to Brook ${ }^{12}$ ) and bioelectrical impedance (body fat calculated according to the method of Davies and Gregory $^{13}$ ).

\section{STATISTICAL METHODS}

The Quetelet BMI for an individual is defined as $y=w / h^{2}$, where $w$ and $h$ are the individual's weight (in $\mathrm{kg}$ ) and height (in $\mathrm{m}$ ) respectively. The distribution of BMI in a population is generally age dependent, and, at a particular age say $t$ years, tends to be positively skewed. Let $Y_{\mathrm{t}}$ represent BMI at age $t$ years and denote its median by $M(t)$ and its coefficient of variation by $S(t)$. A Box-Cox power transformation of $Y_{\mathrm{t}}$ given by

$$
Z=\frac{\left[\frac{Y t}{M(t)}\right]^{L(t)}-1}{L(t) S(t)}
$$

can be made so that $Z$ has approximately a standard normal distribution (that is, Gaussian, with mean 0 and standard deviation 1) by making a suitable choice of the power, $L(t)$.

Once estimates of $L(t), M(t)$, and $S(t)$ are obtained for age $t$ years, the $\alpha$ centile for the BMI distribution at age $t$ can be determined from

$$
M(t)\left[1+L(t) S(t) z_{\alpha}\right]
$$

where $z_{\alpha}$ is the $\alpha$ centile of the standard normal distribution. Centile curves can then be plotted against age, $t$, for selected values of $\alpha$.

B

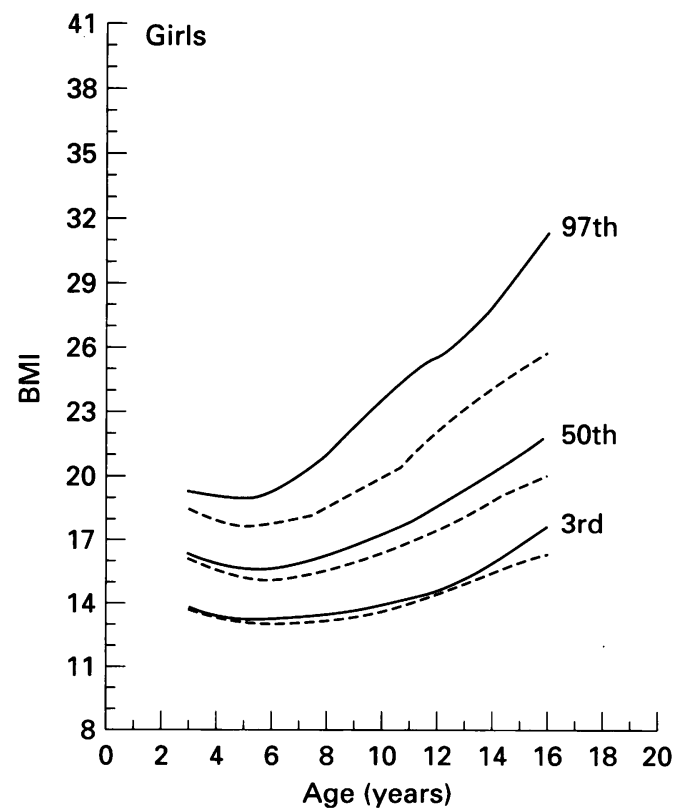

Figure 1 Variation in BMI for $(A)$ boys and (B) girls throughout childhood comparing Tayside with French centiles. 
A

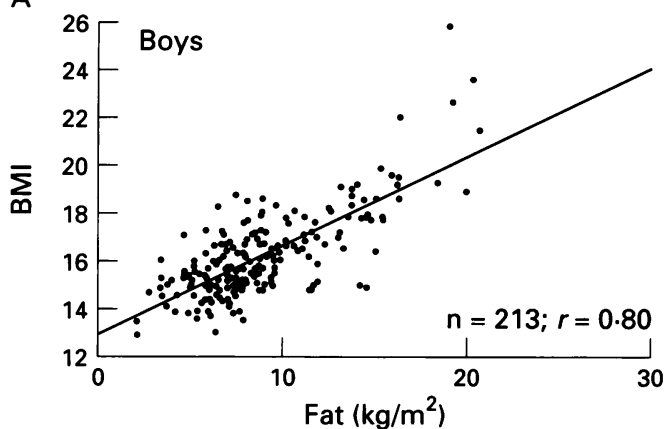

B

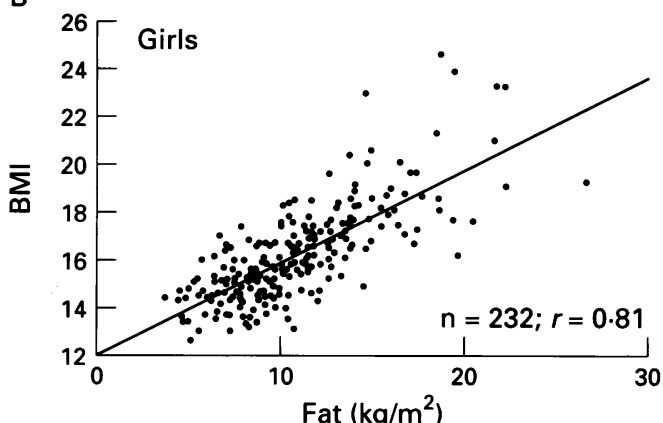

Figure 2 Relationship of BMI with body fat estimation from skinfold measurements in $(A)$ boys and (B) girls aged 7 and 8 years.

Cole called this approach to calculating centile curves the LMS method, ${ }^{14}$ and Cole and Green show how to estimate smooth curves for $L(t), M(t)$, and $S(t)$ using a penalised likelihood method. ${ }^{15}$

Correlation coefficients were calculated between BMI values and estimates of body fat derived from skinfold and bioelectrical impedance measurements in order to gauge the effectiveness of BMI in assessing body fatness. This was done for boys and for girls separately.

\section{Results}

The emphasis of the longitudinal growth study was on height and $90 \%$ of all children had this measurement recorded but only $66 \%$ of the child population had both height and weight data returned. The children who were not weighed were distributed randomly throughout the population.

Smoothed LMS values for BMI calculated at six monthly intervals using the method of Cole and Green ${ }^{15}$ are given in the table. Centile lines for the 3rd, 50th, and 97th centiles were plotted for boys and girls separately, and compared with the previously published French charts (fig 1). Figures 2 and 3 show plots of BMI against skinfold and bioelectrical impedance for 7 and 8 year old boys and girls.

Overall, BMI curves from this study had a similar shape to the published French curves. However, there was a marked difference in the centiles. While the $3 \mathrm{rd}$ and 50th centiles were comparable, the 90th centile of the Tayside children aligned to the 97th centile of the French data. There appears to be a marked

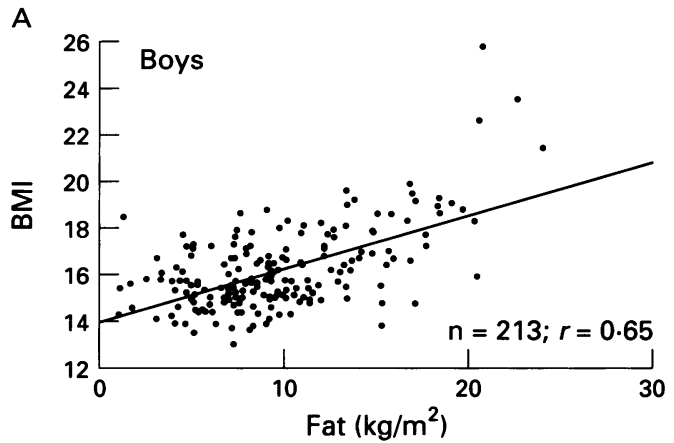

increase in the skewness of the Tayside children to the higher BMI values. They demonstrate adiposity rebound at between 5 and 7 years. The upper centiles of the BMI distribution in this study are noticeably larger at all ages, most particularly for the girls, than the corresponding centiles from the French study.

The $M$ values in the table show that up to adiposity rebound, at age 5 to 7 years, boys tend to have a larger BMI than girls, but after it, the position is reversed, and the difference increases throughout adolescence. The $S$ values in the table show that variation in $\mathrm{BMI}$ is greater for girls than boys throughout childhood, although by the age of 16 it is starting to decline for girls, but is still increasing for boys. Generally the $\mathrm{L}$ values in the table are higher for girls than for boys, indicating that BMI skewness is somewhat less for girls than boys.

\section{Discussion}

The data derived from the Tayside Growth Study shows that BMI alters significantly throughout childhood. With such a large data set, it was possible to estimate the distribution of BMI at increments of down to $0 \cdot 1$ year. The recent LMS statistical method of Cole ${ }^{14}$ allowed for the wide variation of shape in growing children and gave a valid index reflecting body fatness in children. Correlations with estimations of body fat from skinfold measurements and total body water, although only for children aged 7 and 8 years, agreed with similar measures in other studies. ${ }^{16}$ Body fat estimates in other age groups would be

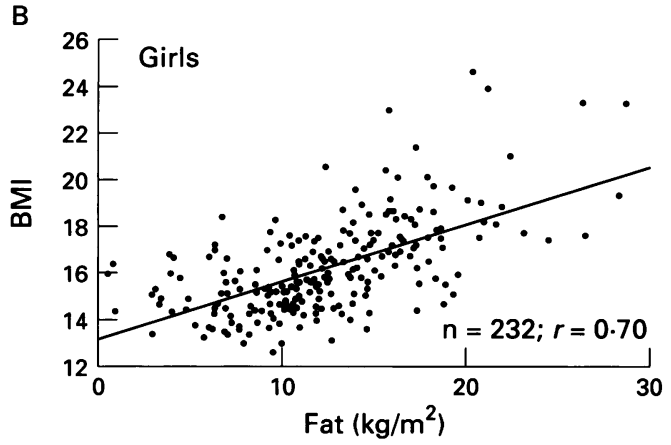

Figure 3 Relationship of BMI with body fat estimation by bioelectrical impedance in $(A)$ boys and $(B)$ girls aged 7 and 8 years. 
useful to confirm the robustness of the BMI standards.

The shape of the BMI curves is very similar to the published French data of Rolland-Cachera over the whole age range. The distribution of BMI values was positively skewed to a greater extent than in the French study. The data for the French standards were collected from 1956 to 1979; higher Tayside values may reflect a secular upward trend or that Scottish children are heavier for their height as has been suggested previously. ${ }^{17}$ Possible secular trends in obesity have been suggested by American and European studies indicating a definite increase in obesity in children. ${ }^{18-20}$ It is, therefore, important to have current British BMI centile charts to look at regional differences within the UK and compare with other countries.

By producing appropriate standards for our population we are able to identify children at the extremes of body fatness. The actual values of BMI for children at risk have yet to be defined. Our child population is progressively becoming taller and heavier (J V Freeman et al, personal data) but this may not necessarily be to their advantage and further studies are required to examine the effect of this increased body mass on morbidity and mortality. In a Belgian study of 6-12 year old children measures of blood pressure, fasting triglycerides, and insulin were significantly correlated with BMI and this relationship was most pronounced among children whose BMI was above the 75th centile ( $M$ Guillaume, presentation at International Congress on Obesity Management, Antwerp 1993).

Charting BMI as part of continuing child health surveillance may identify at an early age children who are likely to become obese adults. By tracking the pattern of variation in BMI over a long period, the French study has shown that the age of BMI rebound relates to obesity in adulthood. ${ }^{4}$ Rebound is the age when an individual's BMI curve is at its nadir. Data from longitudinal studies of Tayside BMI values are being collected with the development of centile charts for children. With this data it may be possible to identify patterns of childhood growth that lead to adult obesity and risk factors for cardiovascular disease. It is imperative that anthropometric data are continued to be collected throughout childhood, so that further secular trends in obesity can be detected.

We thank Dr T J Cole, Dr R Jung, and Professor M Preece for statistical advice in the preparation of this study. EMW was supported by the Clinical Resource and Audit Group of the supported by the Clinical Resource
Scottish Office and Kabi Pharmacia.

1 Jung R, Chong P. The management of obesity. Clin Endocrinol (Oxf) 1991; 35: 11-20.

2 Hawk L, Brook C. Influence of body fatness in childhood on fatness in adult life. $B M \mp$ 1979; i: 151-2.

3 Lloyd J, Wolff O, Whelan W. Childhood obesity: a long-term study of height and weight. $B M \mathcal{F}$ 1961; ii: $145-8$.

4 Rolland-Cachera MF, Deheeger M, Bellisle F, Sempe M, Guilloud-Bataille $M$, Patois $E$. Adiposity rebound in children: a simple indicator for predicting obesity. $A m \mathcal{F}$ Clin Nutr 1984; 39: 129-35.

5 Cernerud L. Height and body mass index of seven-year-old Stockholm schoolchildren from 1940 to 1990 . Acta Paediatr 1993; 82: 304-5.

6 Serdula M, Ivery D, Coates R, Freedman D, Williamson D, Byers T. Do obese children become obese adults? A Byers T. Do obese children become obese adults?
review of the literature. Prev Med 1993; 22: 167-77.

7 Garrow J. Obesity and related diseases. Edinburgh: Churchill Livingstone, 1988.

8 Rolland-Cachera MF, Sempe M, Guilloud-Bataille $M$, Patois E, Pequignot-Guggenbuhl, Fautrad V. Adiposity indices in children. Am f Clin Nutr 1982; 36: 178-84.

9 Cole TJ. Weight-stature indices to measure underweight, overweight and obesity. In: Himes J H, ed. Anthropometric assessment of nutritional status. New York: Wiley-Liss, 1991: 83-111.

10 Rolland-Cachera MF, Cole T, Sempe M, Tichet J, Rossignol C, Charraud A. Body mass index variations: centiles from birth to 87 years. Eur f Clin Nutr 1991; 45: 13-21.

11 Smith A, Chinn S, Rona R. Social factors and height gain of primary schoolchildren in England and Scotland. Ann Hum Biol 1980; 7: 115-24.

12 Brook C. Determination of body composition of children from skinfold measurements. Arch Dis Child 1971; 46: $182-4$.

13 Davies PSW, Gregory JW. Body water measurements in growth disorders. Arch Dis Child 1991; 66: 1467.

14 Cole TJ. Fitting smoothed centile curves to reference data (with discussion). Fournal of the Royal Statistical Society $A$ 1988; 151: 385-418.

15 Cole TJ, Green PJ. Smoothing reference centile curves: the LMS method and penalised likelihood. Stat Med 1992; 11: 1305-19.

16 Rolland-Cachera MF, Deheeger M, Guilloud-Bataille M. Tracking the development of adiposity from one month of age to adulthood. Ann Hum Biol 1987; 14: 219-29.

17 Stark $\mathrm{O}$. The weight of British and French children. Lancet 1986; i: 862.

18 Jonides L. Childhood obesity: an update. Fournal of Paediatric Health Care 1990; 4: 244-51.

19 Boreham C, Savage J, Primrose D, Cran G, Strain J. Coronary risk factors in schoolchildren. Arch Dis Child 1993; 68: 182-6.

20 Gortmaker SL, Dietz WH, Sobol AM, Weber CA. Increasing pediatric obesity in the United States. Am $\mathcal{f} D$ is Child 1987; 141: 535-40. 